\title{
Construction and Evaluation of a Uniaxial Mechanical Actuated Vibration Shaker
}

\author{
Hameed D. Lafta* Nasrat K. Murad** Ihasan J.Khamas ${ }^{* * * *}$ \\ Tebin F. Abdalla***** \\ *,**College of Technical Engineering/Sulaimani Polytechnic University \\ ***,**** Sulaimani Technical Institute/ Sulaimani Polytechnic University \\ *Email: Hameed.lafta@ spu.edu.iq \\ **Email: nasrat.kareem@yahoo.com \\ ***Email: Ahsanjbr@yahoo.com \\ ****Email: Tebeenfaraidwn2000@yahoo.com
}

(Received 22 February 2017; accepted 11 October 2017)

https://doi.org/10.22153/kej.2018.10.006

\begin{abstract}
In the present paper a low cost mechanical vibration shaker of rotating unbalanced type with uniaxial shaking table was designed and constructed in an attempt to provide opportunities for experimental testing and application of vibration in experimental modal analysis, stress relief of weldments, effect of vibration on heat transfer and seismic testing of civil engineering structures. Also, it provides unexpressive solution to enhance the knowledge and technical skills of students in mechanical vibration laboratory. The shaker consists of a five main parts shaker frame, shaker table, flexible support, drive motor, and eccentricity mechanism. The experimental results show that the amplitude of the shaker is increased with increasing the frequency ratio and the maximum value was attained near the resonance condition. Also, the magnitude of amplitude is increased with increasing the eccentric mass and eccentricity values. A reasonable agreement with theoretical results shows that the shaker can be used with reliable results in vibration testing purposes. Also, in this paper, the frequency ranges of the shaker were determined for constant displacement and for constant acceleration tests to satisfy all the frequency limitation requirements of the mechanical shaker.
\end{abstract}

Keywords: Rotating Unbalance, Uniaxial shaker, Vibration Shaker.

\section{Introduction}

Academic exposure to vibration experimentation and instrumentation usually arises in relation to learning, training, and research. Generally, an experimental vibration system consists of four main subsystems, and the excitation system is one of these four integral parts [1]. The excitation system serves to generate specific signal in a controlled manner through a device which it is called vibration exciter. Thus, vibration exciter or shaker is equipment can be used to produce vibration motion to test object under different excitation conditions of forces and displacements through a given range of frequencies.

Nitinkumar Anekar, et.al [2] state that certain machines and structures that develop or subjected to excessive vibrations during their life may be required to make a diagnostic vibration analysis to prevent an impending failure of some components, and such components can be tested using vibration exciters. 
In designing of vibration shaker, three specifications are of primary importance: the force rating, the power rating, and the stroke rating (maximum displacement). Force and power ratings are particularly useful in moderate to high frequency excitations and the stroke rating is the determining factor for low frequency excitations. Clarence W. de Silva [1] presented a procedure to determine conservative estimates for these parameters in selecting of a specified vibration exciter.

Robert L. Norton [3] provides basic information of designing of small components included in exciter design similar to nuts, bolts, springs, structure of frame, selection of motor and other design considerations.

Signal acquisition and modification is an important subsystem in vibration experimentation system. The instrumentation systems and techniques for vibration measurement are key factors to ensure the quality of the measured data and therefore there are many practical implications that must be taken into account [4]. S. S. Rao [5] provides information on vibration analysis, signal acquisition and vibration instruments. Also, the effects of viscous and coulomb damping are discussed and calculation of equivalent viscous damping is presented.

During high level vibration test on a high mass specimen, the test engineer is often facing difficulty to pass properly the specified vibration level due to coupling between the specimen and the shaker, thus Sébastien Hoffait and et.al. [6] they are presented a methodology to define a virtual shaker testing simulator. The first step involves the dynamic identification of a $80 \mathrm{kN}$ shaker performed thanks to measurements (modal analysis and sine sweep).The second step is the definition of the physic represented in the simulator Two test cases are described to demonstrate the possibilities offered by the simulator.

Amongst different types of vibration exciters a mechanical vibration exciter is significantly less expensive than the other types and no need for high skill operation maintenance. Thus, the present work is devoted to construct a mechanical vibration exciter in an attempt to provide opportunities in experimental testing and application of vibration in different research area, such as, experimental modal analysis for structures, stress relief for weldments by vibration, enhancement of heat transfer, in heating and cooling system, by application of vibration, and can be used for prototype testing of civil engineering structures (seismic testing). Also, this shaker provides unexpressive solution for motivating students to validate theories related to the forced vibration in mechanical vibration laboratory. Accordingly, a low cost mechanical vibration shaker of rotating unbalanced type with uniaxial shaking table was designed, manufactured and tested to be reliable and applicable for vibration simulation and testing purposes at different frequencies and amplitudes.

\section{Vibration Exciters}

Vibration experimentation may require an external exciter to generate the necessary vibration. This is the case in controlled experiments such as product testing, determination of the dynamic characteristics of machines and structures, simulation, and testing of materials properties where a specified level of vibration is applied to the test object and the resulting response is monitored. A variety of vibration exciters are available, with different capabilities and principles of operation. Three basic types of vibration exciters (shakers) are widely used: hydraulic shakers, mechanical shakers, and electromagnetic shakers. The operation-capability ranges of typical exciters in these three categories are summarized in Table 1. Vibration Shaker may be able to reproduce motion in only one horizontal direction (uniaxial), or in one horizontal and the vertical direction (biaxial), or in both horizontal directions and the vertical direction (triaxial). Triaxial shakers are the most realistic but also more expensive. Many tests and much research are consequently done on uniaxial or biaxial vibration shakers [7]. 
Table 1,

Typical Operation-Capability Ranges for Various Vibration Shaker Types [1].

\begin{tabular}{|c|c|c|c|c|c|c|}
\hline \multicolumn{7}{|c|}{ Typical Operation capability } \\
\hline Shaker type & Frequency & $\begin{array}{l}\text { Maximum } \\
\text { Displacement } \\
\text { (stroke) }\end{array}$ & $\begin{array}{l}\text { Maximum } \\
\text { Velocity }\end{array}$ & $\begin{array}{l}\text { Maximum } \\
\text { Acceleration }\end{array}$ & Maximum Force & $\begin{array}{l}\text { Excitation } \\
\text { Waveform }\end{array}$ \\
\hline $\begin{array}{l}\text { Hydraulic } \\
\text { (electrohydraulic }\end{array}$ & $\begin{array}{l}\text { Intermediate } \\
0.1-500 \mathrm{~Hz}\end{array}$ & $\begin{array}{l}\text { High } \\
20 \mathrm{in} . \\
50 \mathrm{~cm}\end{array}$ & $\begin{array}{l}\text { Intermediate } \\
50 \mathrm{in} . \mathrm{s}^{-1} \\
125 \mathrm{cms}^{-1}\end{array}$ & $\begin{array}{l}\text { Intermediate } \\
20 \mathrm{~g}\end{array}$ & $\begin{array}{l}\text { High } \\
100,000 \mathrm{Ibf} \\
450,000 \mathrm{~N}\end{array}$ & $\begin{array}{l}\text { Average } \\
\text { flexibility } \\
\text { (simple to } \\
\text { complex and } \\
\text { random }\end{array}$ \\
\hline $\begin{array}{l}\text { Inertial } \\
\text { (counter-rotating } \\
\text { mass }\end{array}$ & $\begin{array}{l}\text { Low } \\
2-50 \mathrm{~Hz}\end{array}$ & $\begin{array}{l}\text { Low } \\
1 \mathrm{in.} \\
2.5 \mathrm{~cm}\end{array}$ & $\begin{array}{l}\text { Intermediate } \\
50{\mathrm{in} . \mathrm{s}^{-1}} \\
125 \mathrm{cms}^{-1}\end{array}$ & $\begin{array}{l}\text { Intermediate } \\
20 \mathrm{~g}\end{array}$ & $\begin{array}{l}\text { Intermediate } \\
1000 \mathrm{Ibf} \\
4500 \mathrm{~N}\end{array}$ & Sinusoidal only \\
\hline $\begin{array}{l}\text { Electromagnetic } \\
\text { (electrodynamic) }\end{array}$ & $\begin{array}{l}\text { High } \\
2-10,000 \mathrm{~Hz}\end{array}$ & $\begin{array}{l}\text { Low } \\
1 \mathrm{in.} \\
2.5 \mathrm{~cm}\end{array}$ & $\begin{array}{l}\text { Intermediate } \\
50 \mathrm{in}^{-1} \\
125 \mathrm{cms}^{-1}\end{array}$ & $\begin{array}{l}\text { High } \\
100 \mathrm{~g}\end{array}$ & $\begin{array}{l}\text { Low to } \\
\text { intermediate } \\
450 \mathrm{Ibf} \\
2000 \mathrm{~N}\end{array}$ & $\begin{array}{l}\text { High accuracy } \\
\text { and flexibility } \\
\text { (simple to } \\
\text { complex and } \\
\text { random) }\end{array}$ \\
\hline
\end{tabular}

\section{Mechanical Vibration Exciters}

In mechanical exciters, the force drives the shaking table is generated by inertia forces (accelerating masses), and the generated force is sinusoidal in nature and it's limited by the strength of the shaking frame [1]. A variety of mechanical vibration exciters are available with different operation mechanisms, such as: Scotch yoke, rotating unbalance mass and eccentric cam. In the present work, a mechanical exciter of unbalance rotating type is considered.

The general arrangement of a counter rotating unbalance mass exciter is shown in Fig.1 [1]. It can be seen that, the generated excitation force is sinusoidal with frequency of $\omega$ and amplitude of $\left(2 \mathrm{me} \square \omega^{2}\right)$ which is directly proportional to the square of magnitude of the excitation frequency $\left(\omega^{2}\right)$. Consequently, the frequency and amplitude of the excitation force can be varied over a range of interest by incorporating a variable speed motor. Also, the amplitude can be varied by varying the magnitudes of both the eccentricity (e) and the unbalance mass (m). However, different mechanisms are used to produce the excitation force.

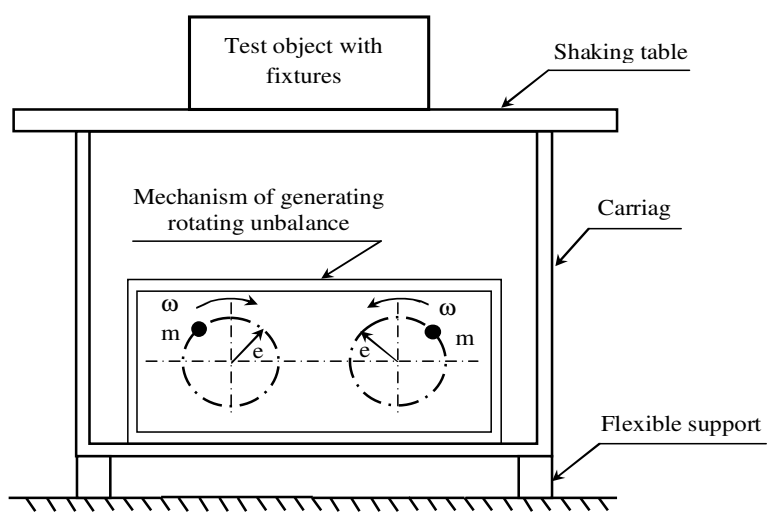

Fig. 1. General arrangement of rotating unbalance vibration shaker.

In rotating unbalance vibration shaker, as shown in Fig.1, the generated force is directly transferred as a reaction force to the shaking table (test), on which the test object is mounted, via the carriage. The carriage with the whole system is mounted on a flexible support. In dynamic testing of large structures, the carriage can be mounted directly on the structure.

The main advantages of mechanical vibration exciters are significantly less expensive than other types of vibration exciters. Their sinusoidal generated forces are virtually undistorted when sinusoidal shaking force test is required and their limitation is determined by the strength of their carriage frame, [1]. The main limitations or disadvantages of these exciters they are not capable of producing complex, random vibration, and constant force testing. Also, their frequency range of operation and maximum velocity and acceleration are low to intermediate compared with other types of shakers. 


\section{Mathematical Background}

Unbalance in rotating machine is a common source of vibration exciter. A simple model of rotating unbalance machine is shown in Fig. 2 [5]. The total mass of the machine is $\mathrm{M}$, and there are two eccentric masses, $\frac{m}{2}$ with an eccentricity (e), rotating in opposite directions with a constant angular velocity $(\omega)$.

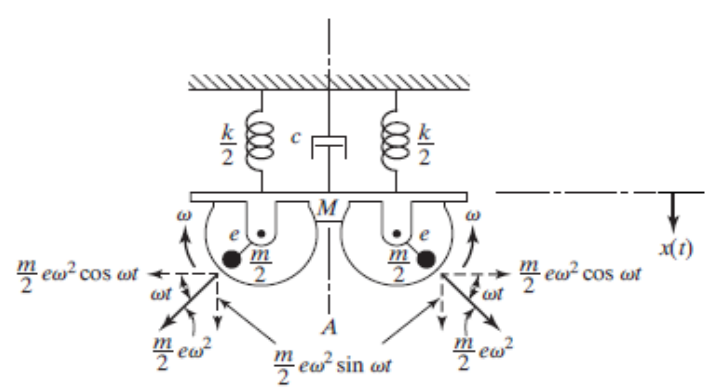

(a)

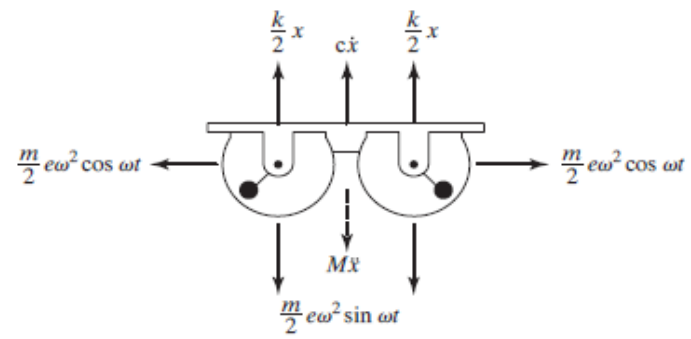

(b)

Fig. 2. Rotating unbalanced masses.

From geometrical of the system, it can be seen that the horizontal components of forces are equal and opposite in direction, thus, they are one cancel each other. However, the vertical components of excitation forces are added together and act along the axis of symmetry A-A. Let, $\mathrm{x}$, be the displacement of the nonrotating mass (M-m) from the static equilibrium position. Then, the displacement of rotating unbalances mass $(\mathrm{m})$, is $(x+e \sin a t)$, and the equation of motion of the system can be obtained using Newton's second law as follows:

$-k x-c \dot{x}=(M-m) \ddot{x}+m \frac{d^{2}}{d t^{2}}(x+e \sin \omega t)$

Where $\mathrm{c}$ and $\mathrm{k}$ are the damping and spring constants of the system.

Re-arranging the equation above, then:-

$M \ddot{x}+c \dot{x}+k x=m e \omega^{2} \sin \omega t$

The particular solution to the preceding equation is a steady-state oscillation of the system with the same frequency $\omega$ as that of the excitation. Thus the particular solution can be assumed:-
$x=X \sin (a t-\phi)$

The amplitude and phase shift, can be obtained by substituting Eq. (3) into Eq. (2). Thus, the amplitude and phase shift are given by:-

$$
\begin{aligned}
& X=\frac{m e \omega^{2}}{\sqrt{\left(k-M \omega^{2}\right)^{2}+(c \omega)^{2}}} \\
& \tan \phi=\frac{c \omega}{k-M \omega^{2}}
\end{aligned}
$$

These equations can be further expressed in terms of the following quantities:-

$$
\begin{aligned}
& \omega_{n}=\sqrt{\frac{k}{M}} \\
& c_{c}=2 M \omega_{n} \\
& \varsigma=\frac{c}{c_{c}} \\
& \frac{c \omega}{k}=2 \varsigma \frac{\omega}{\omega_{n}} \\
& r=\frac{\omega}{\omega_{n}}
\end{aligned}
$$

Substituting $\omega_{\mathrm{n}}, \zeta$, and $\mathrm{r}$ in Eqs. (4) and (5), then the nondimensional forms are given by:-

$$
\begin{aligned}
\frac{M X}{m e} & =\frac{r^{2}}{\sqrt{\left(1-r^{2}\right)^{2}+(2 \varsigma r)^{2}}} \\
\tan \phi & =\frac{2 \varsigma r}{1-r^{2}}
\end{aligned}
$$

The variation of the amplitude ratio $\left(\frac{M X}{m e}\right)$ and the phase angle $(\phi)$ versus frequency ratio $\mathrm{r}$ for different values of $(\zeta)$ are shown in Fig. 3 [5].

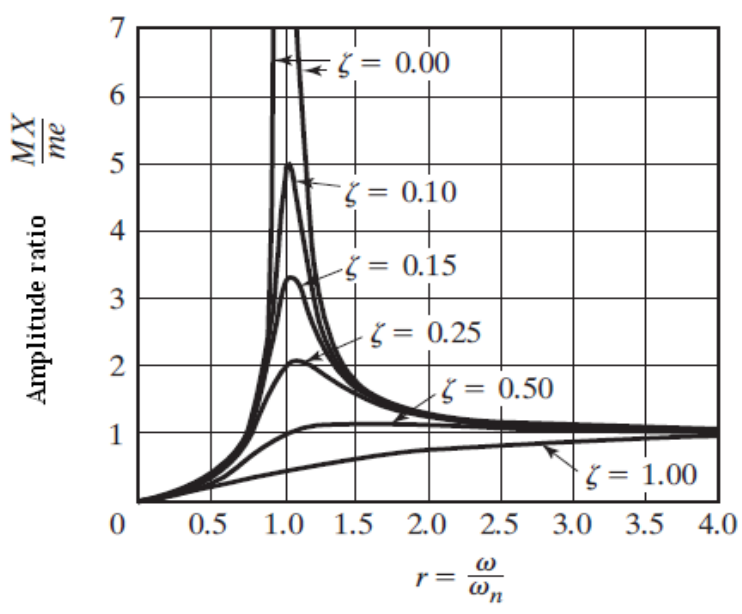

(a) 


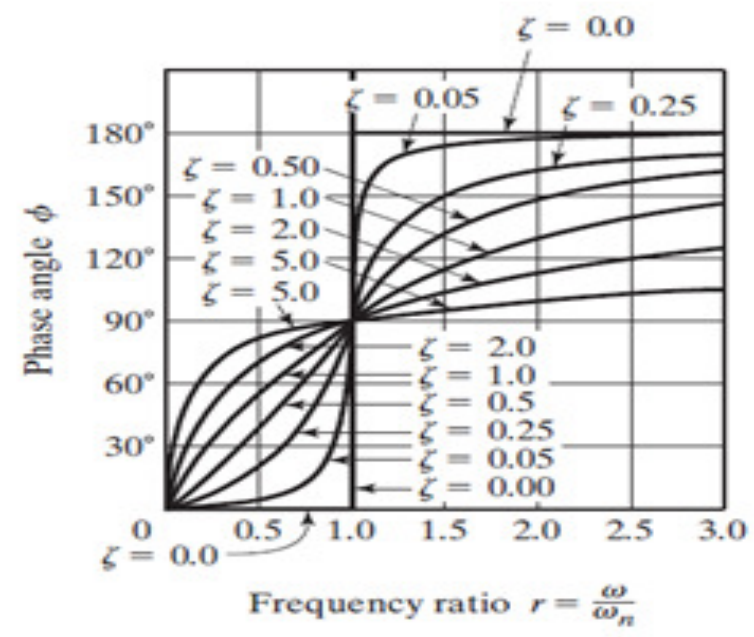

(b)

Fig. 3. Variation of amplitude ratio and phase angle versus frequency ratio for different values of $\zeta$. [5]

From graphs shown in Fig.3, is observed that, all curves of the amplitude ratio is beginning at zero and attain its maximum values near resonance condition. Also, at high frequency ratio, the amplitude ratio equal to unity irrespective of the damping values, in other words, the effect of the damping on the system amplitude can be neglected.

\section{Design Considerations and Construction}

In vibration experimentation and dynamic system tests, the reproduction of accurate dynamic signals with a vibration shaker it may be considered a very important aspect to achieve reliable and meaningful results. However, the distortion of the desired signal depends on the dynamic characteristics of the subsystems of the shaking table-payload system and their interaction [8]. Thus, the design and construction of a vibration shaker was carried out with keep in mind that all the design considerations should be satisfied in order to meet the dynamic specifications of mechanical vibration shakers shown in table 2.

On the basis of the aforementioned considerations, a uniaxial mechanical actuated vibration shaker is designed and constructed. The mechanical actuating mechanism is of a rotating unbalance type. The shaker consists of a five main parts: shaker frame, shaker table and carriage assembly, flexible support, drive motor, and eccentricity mechanism, an overview of the shaker is shown in Fig.4.

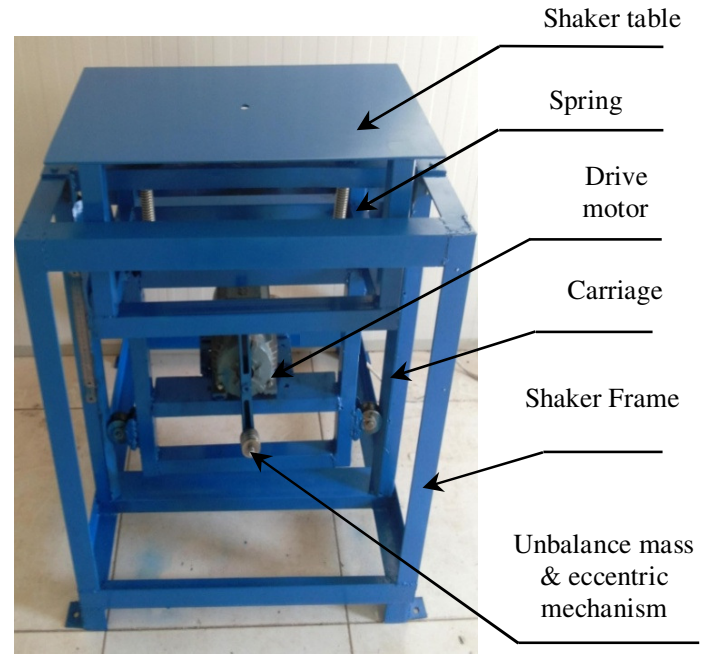

Fig. 4. Overview of the mechanical vibration shaker.

The shaker frame is constructed by using right angle section of size of 4 inches made of structural steel with overall dimensions of $(40 * 80 * 80) \mathrm{cm}$ of the upper part and $(80 * 80 * 80)$ $\mathrm{cm}$ of the lower part with tapered front. The shaker table, which it is used to support the test object, is made of steel plate with overall dimensions of $(40 * 20 * 0.4) \mathrm{cm}$. The shaker table is rigidly attached to the moving part which it is called carriage. The carriage is made of square section structural steel of size 2 inches, and it is allowed to move vertically via two guide rails fixed to the shaker frame and four rollers fixed to the carriage frame. The carriage is suspended vertically via two springs are attached to the upper part of the shaker frame. The springs are tested to satisfy all the requirements of static and dynamic loading conditions [3].

The schematic diagram of the shaker with the measuring instruments is shown in Fig. (5).

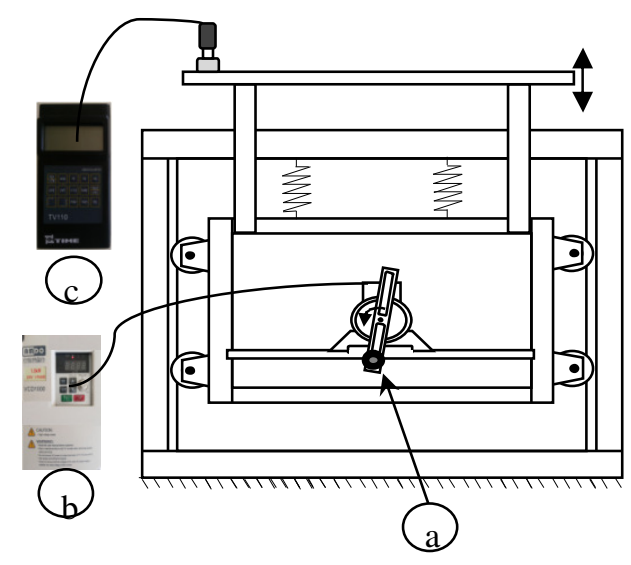

Fig. 5. Schematic diagram of the shaker with the measuring instruments 
The shaking force of this mechanical vibration shaker is generated by using an eccentric mass fixed to long slotted bar by T-bolt (see Fig. (6.a)). The slotted bar is made of steel hollow square section of $5 \mathrm{~cm}$ and the slots is produced by using $\mathrm{CN}$ milling machine to satisfy all the requirements of static and dynamic balancing. The slot bar can be provided an eccentricity range between (3-15) $\mathrm{cm}$. Also, the T-bolt supports up to $0.5 \mathrm{~kg}$ of eccentric mass. In this manner, the magnitude of the eccentricity and eccentric mass can be varied easily to produce different excitation forces. The slotted bar and the eccentric mass are driven by variable speed motor. The drive motor speed is controlled via digital controller (see Fig. (6.b)), thus different excitation frequency can be achieved. The maximum motor excitation frequency is $100 \mathrm{~Hz}$. A vibration meter of (TV110) type is used to measure shaker table amplitude, velocity and acceleration. The meter is provided with an accelerometer that can be fixed to the shaker table by magnetic base (see Fig. (6.c)). The measured signal is processed by using response spectrum analysis and the output is displayed in digital form Three frequency ranges are available for this vibration meter and it is capable of measuring frequency up to $10 \mathrm{kHz}$.

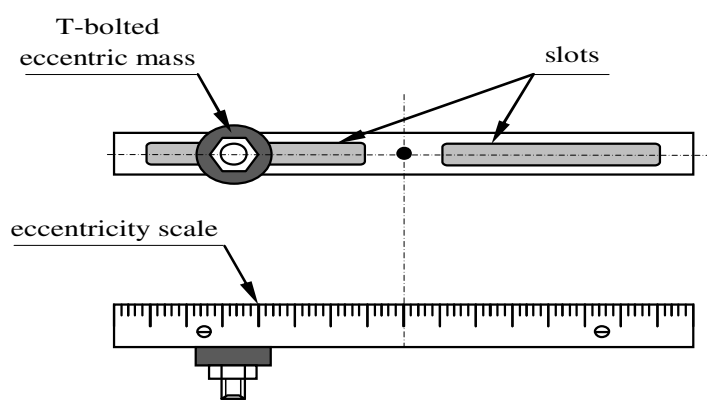

(a)

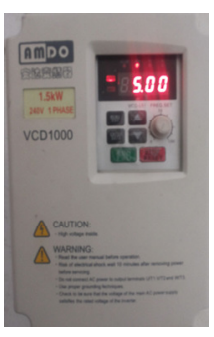

(b)

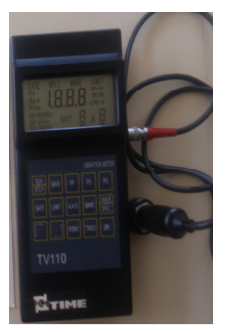

(c)
Fig. 6. Unbalance mass \& eccentric mechanism, motor drive controller, and vibration meter with accelerometer details

\section{Calculation of the System Damping Constant.}

The designed and constructed vibration shaker, in the present work is of a reaction shaker type, and different types of damping may be induced due to sliding friction and structural damping. Thus, the calculation of the system damping in terms of an equivalent viscous damping is achieved to determine the value of the damping ratio of the vibration shaker. Different methods are available in literature to find the system equivalent damping constant $[1,5]$, the most widely used method is called $\mathrm{Q}$ factor or quality factor. The method assumes that the quantity $Q$ is equal to the amplitude ratio at the resonance frequency, then the $\mathrm{Q}$ factor is equal to [5] :-

$Q=\frac{1}{2 \varsigma} \approx \frac{1}{R_{2}-R_{1}}$

Where $R_{1}$ and $R_{2}$ are the frequencies ratio, and referred to as half power points, when the amplitude ratio falls to $\left(\frac{Q}{\sqrt{2}}\right)$, as shown in Fig. 7 .

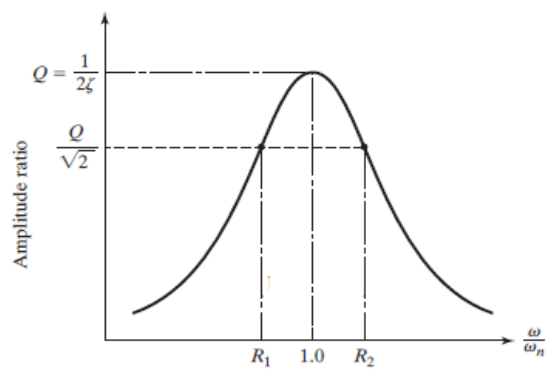

Fig. 7. Harmonic response curve showing half power points.

\section{Results and Discussions}

The specifications, of the vibration shaker constructed in the present work, are shown in table (2), below.

Table 2,

Specifications of the vibration shaker.

\begin{tabular}{ll}
\hline $\begin{array}{l}\text { Shaker table mass (M) } \\
\text { (including all moving parts) }\end{array}$ & $39.5 \mathrm{~kg}$ \\
$\begin{array}{l}\text { Eccentric mass }(\mathrm{m}) \\
\text { Eccentricity (e) }\end{array}$ & $(0.131-0.437) \mathrm{kg}$ \\
$\begin{array}{l}\text { Motor speed (with digital } \\
\text { controller } \pm 0.01 \mathrm{~Hz})\end{array}$ & $(0-60) \mathrm{Hz}$ \\
\hline
\end{tabular}

The natural frequency of the shaker table is calculated to be (4.26) Hz. The vibration shaker is well tested to finding out the actual 
performance of the constructed system through several experimental tests. Using the data given above, the amplitude of the shaker for different range of frequencies are determined experimentally and compared with the theoretical one.

Figs.(8), (9), and (10) show the variation of the shaker amplitude with the frequency ratio $\frac{a}{\omega_{n}}$ for different values of the eccentric mass $(\mathrm{m})$. The reasonable agreement between the theoretical and experimental results, indicate that the shaker can be used with acceptable results in vibration testing purposes.

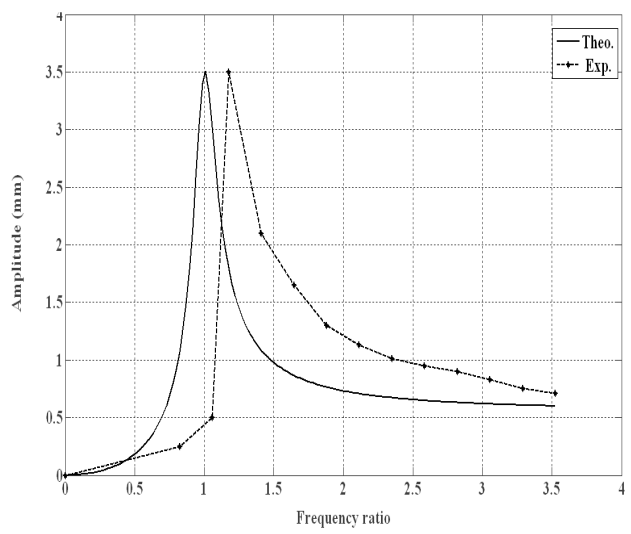

Fig. 8. Shows the variation of the amplitude versus frequency ratio for $\mathrm{m}=0.182 \mathrm{~kg}$, and $\mathrm{e}=\mathbf{0 . 1 2} \mathrm{m}$.

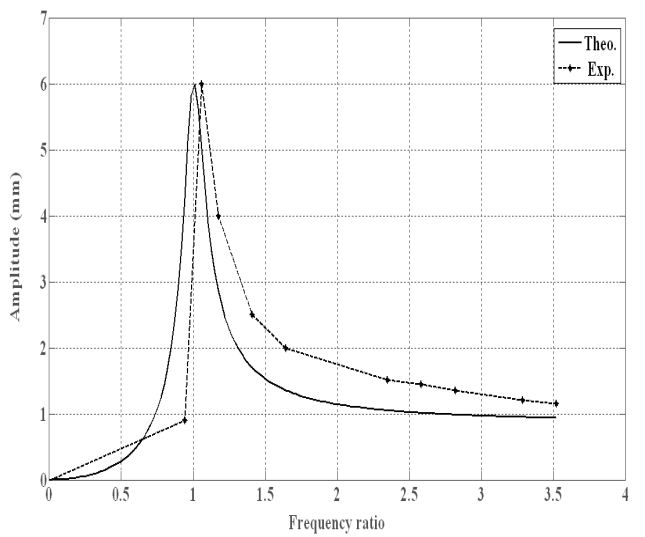

Fig .9. Shows the varaition of the amplitude versus frequency ratio for $\mathrm{m}=0.284 \mathrm{~kg}$, and $\mathrm{e}=0.12 \mathrm{~m}$.

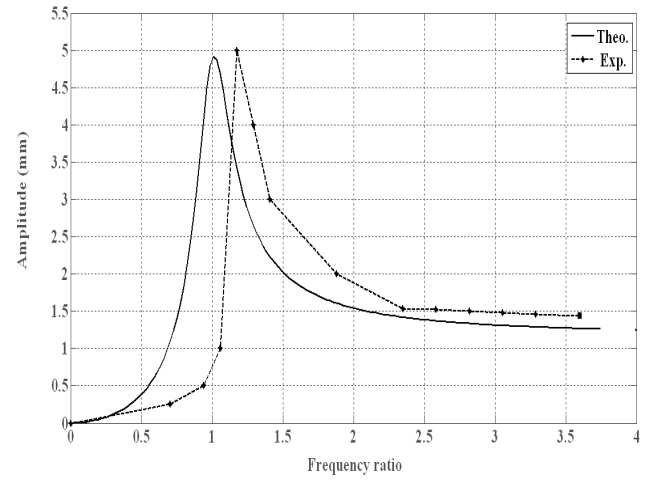

Fig. 10. Shows the varaition of the amplitude versus frequency ratio for $\mathrm{m}=0.386 \mathrm{~kg}$, and $\mathrm{e}=0.12 \mathrm{~m}$.

Figs. (10), (11), and (12), show the variation of the shaker amplitude with the frequency ratio $\frac{\omega}{\omega_{n}}$ for different magnitudes of the eccentricity (e). It is clear that the maximum amplitude produced by the shaker is increased with increasing the eccentricity magnitude, thus the shaker permits to produce different excitation forces in accordance with user requirements.

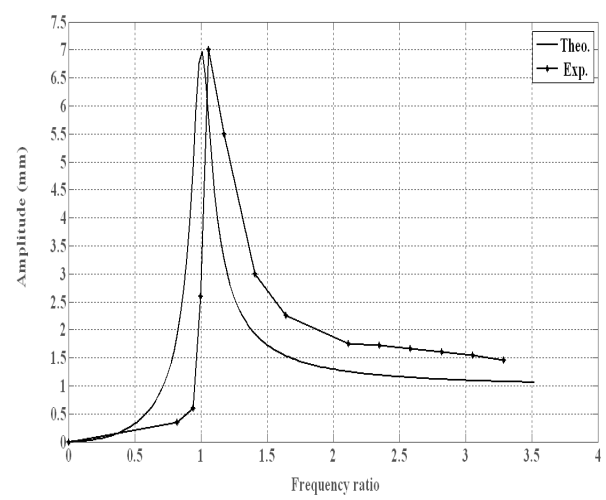

Fig. 11. Shows the varaition of the amplitude versus frequency ratio for $\mathrm{m}=0.386 \mathrm{~kg}$, and $\mathrm{e}=0.1 \mathrm{~m}$.

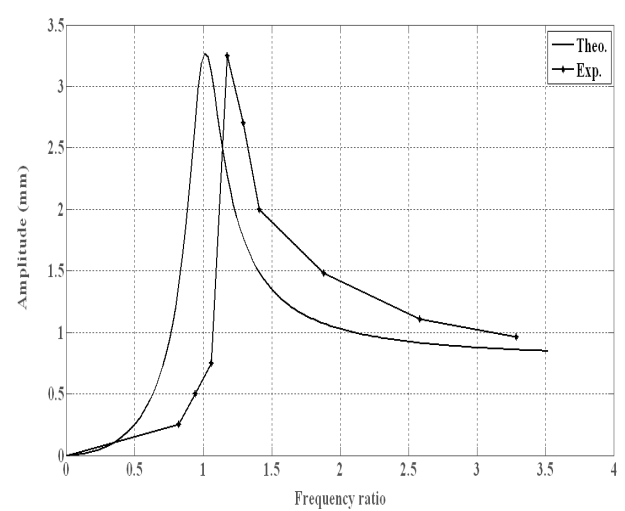

Fig.12. Shows the varaition of the amplitude versus frequency ratio for $\mathrm{m}=0.386 \mathrm{~kg}$, and $\mathrm{e}=0.08 \mathrm{~m}$. 


\section{Dynamic Characteristics and Testing Limitations}

The dynamic characteristics of a vibration shaker, the pay load capacity and testing range, limitations are determined. The capabilityoperation ranges of a vibration shaker are specified by the test object size, displacement, velocity, acceleration and frequency ranges produced by the shaker, and their determination are very important to explain the allowable testing area of the shaker. The present shaker is designed to withstand a testing object of maximum mass of $49 \mathrm{~kg}$, and maximum allowable displacement of $0.5 \mathrm{~cm}$. The frequency range of the shaker is (3-30) Hz. The maximum velocity of the shaker is $13 \mathrm{~cm} / \mathrm{sec}$, and the maximum acceleration does not exceed $2.5 \mathrm{~g}$.

\section{Conclusions}

A mechanical vibration shaker of rotating unbalance type with uniaxial shaking table was designed constructed and tested. The shaker is well tested to determine their dynamic characteristics and limitations. The overall damping factor of the shaker was calculated by using the $Q$ factor method. Also, the effect of rotating unbalance were examined and it is found that the magnitudes of eccentric mass and eccentricity values are controlling the amplitude and force capacity of the vibration shaker. The constructed shaker is designed to withstand a test object of $49 \mathrm{~kg}$ and allowable maximum displacement of $0.5 \mathrm{~cm}$. The vibration testing can be achieved over a range of frequencies of (3-30) $\mathrm{Hz}$, at designing limitation of maximum acceleration of $(2.5 \mathrm{~g})$ and maximum velocity of $(13 \mathrm{~cm} / \mathrm{s})$. The good agreement between the experimental results and the theoretical results, show that the vibration testing can be carried out with reasonable results.

\section{Notation}

c damping constant

$\mathrm{c}_{\mathrm{c}} \quad$ critical damping constant

e eccentricity

$\mathrm{k} \quad$ spring constant

M mass of the shaking table

$\mathrm{m}$ unbalance mass

$\mathrm{r}$ frequency ratio

$\mathrm{X}$ amplitude due to forced oscillation

$\mathrm{x}$ displacement shaker

\section{Greek letters}

$\begin{array}{ll}\omega_{\mathrm{n}} & \text { system natural frequency } \\ \zeta & \text { damping ratio } \\ \omega & \text { forced frequency } \\ \phi & \text { phase of the displacement with respect to } \\ & \text { exciting force. }\end{array}$

\section{Acknowledgment}

The authors would like to thank Mr. Aso Abdulah the engineer at Theory of Machines and Vibration Laboratory for his support, and $\mathrm{Mr}$ Saman Hama Sa'aeed the technician at workshops, for setting up the equipments at technical engineering college at SPU.

\section{References}

[1] Clarence W. de Silva, Vibration Fundamentals and Practice. CRC press LLC.2000

[2] Nitinkumar Anekar, V.V. Ruiwale, Shrikant Nimbalkar, and Pramod Rao " Design and Testing of Unbalance Mass Mechanical Vibration Exciter," IJRET, vol. 3, Issues 8, pp. 107-112, 2014.

[3] Robert L. Norton, "Machine Design: An Integrated Approach," 5th Edition, Pearson 2013.

[4] Everaldo de Barros, Carlos d'Andrade Souto, Leandro Ribeiro de Camargo, Mauro Hugo Mathias "Application of a Computer Sound Card for Measurement of Mechanical Vibrations," Revista Brasileira de Ensino de Fsica, v. 37, n. 4, 4313 (December 2015).

[5] S.S. Rao, Mechanical Vibrations. 5th edition, Pearson Education, Inc. 2011.

[6] Sébastien Hoffait, Frédéric Marin, Daniel Simon, Bart Peeters, and Jean-Claude Golinval, "Measured-based shaker model to virtually simulate vibration sine test". Case Studies in Mechanical Systems and Signal Processing, published by Elsevier 3 May 2016.

[7] Paul Ibanez "An Introduction to Shake Tables for Seismic Testing of Equipment and Glossary of Vibration Terminology". ANCO Engineers, October 2008.

[8] T. Baran, A.K. Tanrikulu, C. Dundar, and A.H. Tanrikulu " Construction and Performance test of a law- Cost shake table". Experimental Techniques July/August 2011. 


\author{
بناء وتقييم هزاز

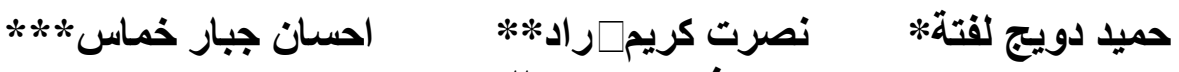

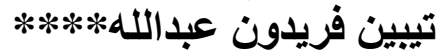

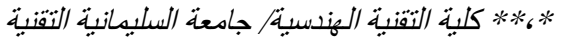

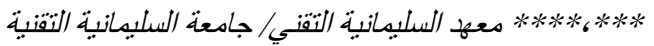

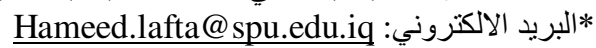

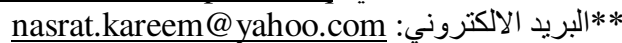 \\ Ahsanjbr@yahoo.com البريد الالكتروني: الإني: \\ Tebeenfaraidwn2000@yahoo.com البريد الالكثروني: الاكتروني:
}

الخلاصة

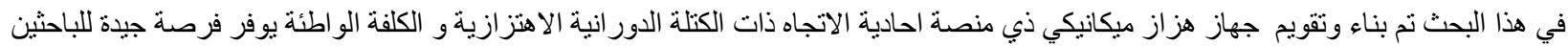

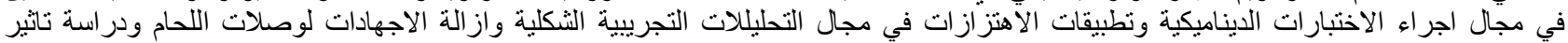

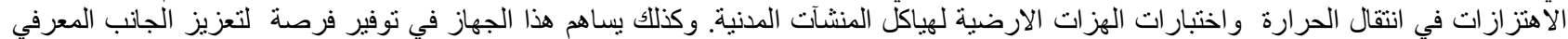

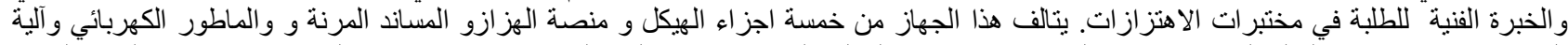

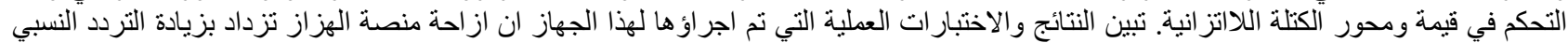

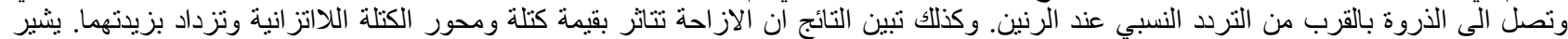

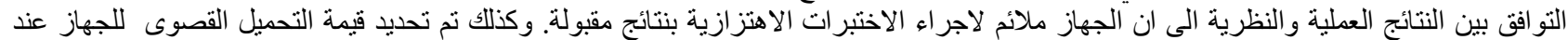

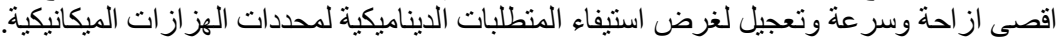

